ESJ Social Sciences

\title{
The Efficiency of Public Spending in Sub-Saharan Africa
}

\author{
Dickson O. Wandeda \\ Wafula Masai \\ Samuel M. Nyandemo \\ University of Nairobi, Kenya
}

Doi:10.19044/esj.2021.v17n19p173

Submitted: 04 January 2021

Accepted: 10 March 2021

Published: 30 June 2021
Copyright 2021 Author(s)

Under Creative Commons BY-NC-ND

4.0 OPEN ACCESS

Cite As:

Wandeda D.O., Masai W. \& Nyandemo S.M. (2021). The Efficiency of Public Spending in Sub-Saharan Africa.

European Scientific Journal, ESJ, 17(19), 173. https://doi.org/10.19044/esj.2021.v17n19p173

\begin{abstract}
In this article, the authors analyze the efficiency of public spending among Sub-Saharan African countries using a panel data for 23 Sub-Saharan Africa countries covering the period 2006-2018. This paper employs two-stage bootstrap output-oriented DEA approach. In addition, this study analyses the sources of distortions in public spending. Results show that the average biascorrected inefficiency score was 48 percent between 2006 and 2018 while the uncorrected inefficiency was 32.3 percent. Institutional quality and domestic saving significantly influence the efficiency of public spending. Hence, there is need for Sub-Saharan African governments to observe fiscal discipline through strengthening of monitoring unit of government expenditure.
\end{abstract}

Keywords: Public spending, efficiency, two-stage bootstrap output-oriented DEA

\section{Introduction}

Governments' intervention in the economy through efficient spending not only enhances long-run growth but are also important in macroeconomic stabilization. With Sub-Saharan African countries (SSA) faced with limited resourc00es, it is crucial to investigate the efficiency of public spending since a marginal change can have a great impact on the attainment of government objectives which are in line with Sustainable Development Goals (SDGs). An empirical finding that details the extent of efficiencies of government 
expenditure is crucial in correcting for government wastages. In addition, caution needs to be taken in budgetary allocation of resources by the government and mechanisms that improve efficiencies of public expenditure.

An effective government accelerates output growth (Rajkumar and Swaroop, 2008). Tanz (2004), for example, suggested that the attainment of economic growth is associated with efficient use of public resources. Sustainable economic growth is possible through sound public finance and efficient public expenditure. Many factors explain cross country income variation. Such covariates include magnitude of the government expenditure multiplier. Different multipliers result in different realizations of change in Gross Domestic Product (GDP). Other covariates include the efficiency in the execution of government public expenditure (Wang and Alvi, 2011).

Empirical studies have demonstrated that African countries are less efficient in fiscal policies compared to regions (Gupta and Verhoeven, 2001). Wastefulness in government spending coupled with constrained domestic resources mobilization has resulted in the rise in public debt. Inefficiencies of government spending have caused public debt to rise in most SSA countries as from 2015 hence African countries run deficit spending. SSA governments have therefore resorted to both internal and external borrowing to finance deficits. However, internal borrowing by SSA countries has created the crowding out problem for private investments. Higher borrowing cost associated with high interest rate on loans has significantly contributed to reduction in local investment and increase in unemployment (Hernández-Catá, Schwab and Lopez-Claros, 2004).

Although adequate public spending is important for sound economic growth, more spending may be ineffective if fiscal discipline is not observed by the government. SSA countries, for instance, are characterized by high levels of corruption (Teorell, et al. 2011). The average Transparency International Corruption Perception Index (CPI) for SSA countries was 2.9 out of the maximum possible 10. High level of corruption in SSA countries is therefore sources of inefficiency in public expenditure. Previous studies have not analysed the determinant of the efficiency of public expenditure for SSA countries. Besides, earlier studies have used different approaches to measure public expenditure efficiency which contributes to the mixed results.

There exist limited studies on the analysis of efficiency of government expenditure in SSA countries. This paper adds to the literature by analysing the status of efficiency of public spending for SSA countries. Information on inefficiency could be utilized by SSA countries to design policies that reduce wastages in public expenditure. In particular, the study analysed the efficiency of different components of government expenditure (Health and education) of SSA countries. Results from this finding are significant for policy actors in understanding the extent of inefficiencies across SSA countries. Secondly, 
environmental factors like institutional quality might influence the efficiency of government expenditure. The study incorporated these exogenous factors in the analysis by examining how institutional quality impacts the efficiency of government spending. Such evidence can provide a framework within which governments can put in place institutional arrangements aimed at fighting corruption to realize sound fiscal policy.

Various studies have used different approaches to measure efficiency of public expenditure. Kimaro et al., (2017) used indexes and performance indicators to measure efficiency of public expenditure for SSA countries. Analyses of efficiency is concerned with providing information on the maximum possible achievement, however, performance indicators used by Kimaro et al., (2017) does not elicit optimal possible outcome (Mandl, Dierx and Ilzkovitz, 2008). This paper contributes significantly by analysing efficiency of public spending for SSA countries by applying Data Envelope Analysis (DEA). DEA is a non-parametric method that measures productive efficiency of decision making units. The approach is very common with studies examining technical efficiency given that it is free from the restriction of a priori functional form and it also allow for multiple output technologies. However, DEA is known to suffer from serial correlation problem. This paper therefore contributes significantly by adopting two-stage bootstrap DEA as suggested by Simar and Wilson (2007). No single study has applied Simar and Wilson approach to estimate the efficiency of government spending in SSA.

The rest of the paper is structured as follows. Section 2 discusses empiricalreview of the efficiency of public spending. Section 3 presents methodological approach and data. Section 4 describes results. Section 5 presents discussion and conclusion.

\section{Literature Review}

Afonso et al., (2005) examined public sector efficiency for twenty three industrialised countries. The study relied on Free Disposal Hull (FDH) analysis. The study found that private sector performance for big governments is 35percent lower than small governments. Similarly, Afonso and Fernandes (200) analysed the spending efficiency for Lisbon municipality. The composite output measure, found that municipalities on average could have reduced resources by 41percent to achieve the same level of output. Rahmayanti and Horn (2010) examined the efficiency score for government spending for 63 developing countries for the period between 1990 and 2003. The study found that developing countries can maximize growth using smaller resources if expenditure is efficiently utilized.

Prasetyo and Zuhdi (2013) examined the efficiency of government spending on human capacity building. The study sampled 81 countries for the period 2006 to 2010. Efficiency was estimated by employing DEA approach. 
The study found that some countries were on the efficiency frontier with only Singapore and Zambia showing positive improvements on efficiency frontier. Hsu (2013) examined government spending efficiency on health for 46 Central Asia countries and Europe and used DEA method. On the average, the overall technical efficiency was found to be 98.8percent and the productivity growth decreased by 7.7 percent annually over the sample period. Chan, et al. (2017) examined the technical efficiency of government spending for 115 countries. The study adopted DEA technique. The study found that efficient government spending enhances growth. Wang and Alvi (2011) measured the relative technical efficiency scores and the determinant of government performance. The study adopted DEA. The result showed that Singapore and Japan were more efficient than the remaining Asian countries. Extreme bounds analysis (EBA) found corruption to be an important factor determining government performance.

Hauner and Kyobe (2010) sampled 114 countries from 1980 to 2006 and used DEA approach. DEA was used to estimate public sector performance (PSP) and public sector efficiency (PSE). The finding showed that efficiency decreases with a rise in spending. Further, results showed that government accountability and control for corruption significantly improves spending efficiency. Herrera and Pang (2005) examined efficiency spending for a sample of 140 developing countries using data from 1996 to 2002. The frontier was estimated by both Free Disposable Hull (FDH) and DEA. The study found an average efficiency score of 0.9. Health and education expenditure for developing countries could have been increased by 10 percent by using the same level of input.Gupta and Verhoeven (2001) analysed the efficiency of government for 37 African countries between 1984 and 1995. The paper used FDH to analyze the relative efficiency of education and health spending. The result showed that African governments are less efficient in spending than the Asia and the Western Hemisphere countries. Inefficiencies experienced in Africa are attributed to relatively high government wages and the intrasectoralallocation of government resources.

\section{Method and data}

Literature has proposed two main techniques in analysing the efficiency of government spending: the non-parametric (DEA or FDH) and the parametric technique (Stochastic frontier). The parametric approach in measuring efficiency imposes a priorifunctional form that relates inputs and the outputs. The non-parametric technique does not impose functional restrictions. Stochastic frontier (SF) has the merit of dealing with random noise while inefficiency in DEA is measured by the deviation from the efficiency frontier (Rayp and Van De Sijpe, 2007). 
The measurement of the efficiency of decision making units (DMUs) is popularly estimated by DEA technique. Charnes, Cooper, and Rhodes (1978) build on Farrell's (1957) technical efficiency (TE) to develop constant returns to scale (CRS). Banker, Charnes, and Cooper (1984) extended the BCC model to the variable-returns-to-scale (VRS) version. Non-parametric approach (DEA) is used in this paper to estimate efficiency of government spending for SSA. DEA has the following advantages: (1) DEA, unlike SFA, does not assume a priori specification of functional form for production technology (2) it is applicable in the case of multiple-output and multiple-input (3) and it does not require distributional assumptions

DEA estimates of technical efficiency (TE) can either be inputoriented or output-oriented. The aim of input-oriented approach is to measure the percentage of input that can be reduced to produce the same level of output. Output-oriented DEA evaluate the proportionate increase in output at the given input level. Both input-oriented and output-oriented DEA approaches produce the same estimates under CRS. However, the scores for these two approaches diverge under VRS. Both approaches are immune to simultaneous equation bias and specification hence they can identify efficient decision making units (DMUs).

Sung (2007) suggested that "when a DMU produces many outputs by employing many inputs, inputs and outputs must be aggregated into an input and an output index, respectively, to enable calculation of a ratio to measure productivity. TE reflects the ability of a DMU to produce the maximum output attainable from a given set of inputs or the ability of a DMU to use the minimum amount of inputs possible to produce a given set of outputs. Using the maximum output criterion, it is assumed that DMU operates at a point on the production possibility set that represents the set of all technologically feasible production plans for a given level of inputs."

According to Charnes, et al. (1987), an equation evaluating efficiency is given by:

$$
\begin{gathered}
\operatorname{Min} \varphi, \lambda^{\varphi} \\
\text { Subject to }-\gamma_{i}+Y \lambda \geq 0 \\
\varphi x_{i}-X \lambda \geq 0 \\
n^{\prime} 1 \lambda=1 \\
\lambda \geq 0
\end{gathered}
$$

Where;

$\varphi$ : is a scalar which lies between 0 and 1. $\varphi$ measures the TE. DMU is considered inefficient if $\varphi$ is less than a unit $(\varphi<1)$. However, DMU is efficient if $\varphi$ equals one unit $(\varphi=1)$; that is DMU is along the frontier. $\lambda$ : is a $(n \times 1)$ vector of scalar values that measures the deviation from frontier for each DMUs (AfonsoandKazemi, 2017). 
$n^{\prime} 1 \lambda=1$ : imposes convexity of the frontier, accounting for variable returns to scale.

$X$ : is input vector of dimension $\mathrm{K}$ by $\mathrm{T}$ that produces $\mathrm{M}$ outputs

$Y:$ is a vector of outputs for the whole period.

The CRS is obtained when $\sum_{t=1}^{T} \lambda_{t}=1$. CRS implies that if you increase input quantity by a given proportion then outputs quantity will increase by the same proportion. However, in the VRS an increase in input quantity by a given proportion will result to less or more proportionate increase in outputs quantity.

DEA has a number of limitations: (1) the estimates do not shed light on the sources of inefficiencies and (2) estimates are computed from a common sample which results to problem of serial correlation. Simar and Wilson (2007) developed two-stage process that remedies estimation problems associated with non-parametric DEA. Simar and Wilson (2007) approach combines efficiency measurement of DEA with regression. DEA efficiency score is used as dependent variable and regression against exogenous variables. Two-step approach yields estimated standard errors and confidence intervals that are free from bias.

Simar and Wilson (2007) consider three variables $\rho_{i}, \chi_{i}$, and $\psi_{i}$ for a sample of $i=1, \ldots, N$ DMUs. $\rho_{i}$ denotes a vector of inputs used in the production process, $\chi_{i}$ is a vector of output realized while $\psi_{i}$ represents a vector of $K$ exogenous variables that influence input-output combination. $\varnothing_{i}$ in output oriented Ferrell (1957) measures the distance between each DMUs' output and the frontier. The inefficiencies by each DMUs is captured by $\emptyset_{i}$. Equation (2) gives Simar and Wilson data generating process for efficiency

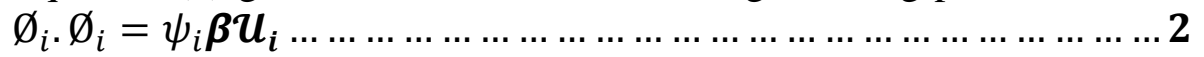

Where $\boldsymbol{\beta}$ denotes the column vector of coefficients. The disturbance term, $\boldsymbol{U}_{\boldsymbol{i}}$, is independent, truncated and such that $\boldsymbol{U}_{\boldsymbol{i}} \sim N(0, \delta)$.

Simar and Wilson (2007) proposed the follow steps in performing two-stage analysis of efficiency;

1. Use DEA to estimate $\emptyset_{i}$ for all DMUs ie $i=1, \ldots \ldots, N$

2. For $\widehat{\emptyset}_{l}>1$, use M DUMs for which $M<N$ in a truncated regression (left-truncated at 1) of $\widehat{\emptyset}_{\imath}$ on $\psi_{i}$ to obtain coefficient estimates of $\widehat{\boldsymbol{\beta}}$ and for variance parameter $\hat{\delta}$ for maximum likelihood.

3. Loop over steps 3.1-3.4 $C_{1}$ times to obtain a set of $C_{1}$ bootstraps estimates $\widehat{\emptyset}_{l}^{c}$ for each DMU $i=1, \ldots, N$, with $c=1, \ldots, C_{1}$.

3.1 For each DMUs $i=1, \ldots, N$, draw an artificial error $\widehat{\boldsymbol{u}}_{\boldsymbol{\imath}}$ from the truncated $\quad N\left(0, \widehat{\boldsymbol{u}_{\boldsymbol{\imath}}}\right)$ distribution with left-truncation at $1-\psi_{i} \widehat{\boldsymbol{\beta}}$.

3.2 Compute artificial efficiency scores $\widehat{\emptyset}_{\iota}$ as $\psi_{i} \widehat{\boldsymbol{\beta}}+\widehat{\mathcal{U}}$ for each

DMU $i=1, \ldots, N$ 
3.3 Generate $i=1, \ldots, N$ artificial DMUs with input quantities $\widehat{\rho_{l}}=\rho_{i}$ and output

$$
\widehat{\psi}_{\iota}=\left(\widehat{\emptyset}_{\imath} / \widehat{\emptyset}_{l}\right) \psi_{i}
$$

3.4 Use the $\mathrm{N}$ artificial DMUs, generated in step 3.3, as a reference in a DEA that yield $\widehat{\emptyset}_{l}{ }^{c}$ for each original DMU $i=1, \ldots, N$.

4. For each DMUs $i=1, \ldots, N$, calculate a bias corrected efficiency score $\widehat{\emptyset}_{l}^{c}$ as

$$
\widehat{\emptyset}_{l}-\left(1 / C_{1} \sum_{C=1}^{C_{1}} \widehat{\emptyset}_{l}^{c}-\widehat{\emptyset}_{l}\right) .
$$

5. Run a truncated regression (left-truncation at 1) of $\widehat{\emptyset}_{l}^{c}$ on $\psi_{i}$ to obtain coefficient estimates of $\hat{\hat{\beta}}$ and an estimate for variance parameter $\hat{\hat{\delta}}$ by maximum likelihood.

6. Loop over steps in 6.1-6.3 $C_{2}$ times to obtain a set of $C_{2}$ bootstraps estimates $\left(\hat{\hat{\beta}}, \hat{\delta}^{c}\right)$ with $c=1, \ldots \ldots, C_{2}$.

6.1 For each DMUs $i=1, \ldots, N$, draw an artificial error $\widehat{\widehat{u}}_{\boldsymbol{\imath}}$ from the truncated $\quad N\left(0, \widehat{\boldsymbol{u}}_{\boldsymbol{\imath}}\right)$ distribution with left-truncation at $1-\psi_{i} \widehat{\boldsymbol{\beta}}$.

6.2 Compute artificial efficiency scores $\widehat{\widehat{\emptyset}}_{l}$ as $\psi_{i} \widehat{\boldsymbol{\beta}}+\widehat{\mathcal{U}}$ for each DMU $i=1, \ldots, N$

6.3 Run a truncated regression (left-truncation at 1) of $\widehat{\emptyset}_{l}$ on $\psi_{i}$ to obtain bootstrap estimates $\widehat{\widehat{\boldsymbol{\beta}}}^{c}$ and $\widehat{\widehat{\boldsymbol{\delta}}}_{\boldsymbol{\imath}}^{c}$ by maximum likelihood

7. Calculate confidence interval and standard error for $\widehat{\boldsymbol{\beta}}$ and $\hat{\hat{\delta}}$.

To obtain consistent inference on efficiency score, this paper used a double-bootstrap procedure as proposed by Simar and Wilson (2007). Based on previous studies (Levine and Renelt, 1992; Saleh and Harvie, 2005; Mankiwet al. 1992; Barro, 1991: Cebula, 2003; Saleh and Harvie, 2005) a number of environmental variables were considered: Institutional quality, inflation, labour force, primary and secondary enrolment, military expenditure and GDP per capita. Following previous studies Afonso and Kazemi (2017), output-oriented DEA was performed since the primary goal of the government is to improve the education level, child mortality and to provide health services that improve life expectancy.

The efficiency measures differ with the assumption about global technology. Efficiency scores differ under the assumptions of VRS and CTRS. Estimates of efficiency under CRS will lead to inconsistent output if technology is not CRS globally (Simar and Wilson 2002).Two-part returns to 
scale test was performed to determine whether to run two-stage bootstrapped DEA under the assumption of CRS or VRS.

Simar and Wilson (2002) therefore suggested the following test:

$\underline{\text { Test \#1 }}$

$$
\begin{gathered}
H_{0}: T \text { is globally CRS } \\
H_{1}: T \text { is VRS }
\end{gathered}
$$

If null hypothesis is rejected a less restrictive null hypothesis may be performed:

Test\#2

$H_{0}: T$ is globally NIRS

$$
H_{1} \text { : T is VRS }
$$

Nonparametric test of independence was done to decide among three types of bootstraps; (1) smoothed homogeneous, (2) smoothed heterogeneous, and (3) sub sampling (heterogeneous). The test was performed under the assumption of VRS.

Panel data of 23 SSA from the year 2006 to 2018 was used. The two inputs used are: health and education expenditure. Outputs are outcomes of these expenditures. For example education outcomes include secondary and primary enrolment while health outcomes comprise life expectancy and infant mortality. Data was sourced from World Development Indicator (2019).

\section{Results}

\subsection{Descriptive statistics}

Table 1 provides summary statistics. Governments are considered DMU's since they employ various inputs (expenditures) to produce outputs to the public. The average education spending was 4.63 percent of GDP with highest expenditure on education at 13.22 percent of GDP. Some SSA countries spend as low as 0.418 percent of GDP on education sector. On the average, SSA countries spend 2.805 percent of GDP towards health sector with maximum expenditure on health at 9.087 percent of GDP. The average primary enrolment is 100.04 percent while secondary enrolment stands at 43.4percent.

Infant mortality averaged 59 infants per 1000 infants while the countries with highest infant mortality between 2006 and 2018 had 110 per 1000 infants compared to countries with the lowest 11 per 1000 infants. GDP per capita for the 23 SSA countries during the study period averaged USD 2181.409. The standard deviation for income per capita is quite high illustrating high variation in GDP per capita across SSA countries. Military expenditure had an average of 1.67 percent of GDP with a standard deviation of 1.16 percent. The average labour force was 52.52 percent while capital formation was 20.51 percent. Six components of institutional quality were considered (Government effectiveness, political stability, rule of law, voice 
and accountability, control of corruption and regulatory quality). All the six composite indicators values averaged below 0 indicating poor governance.

Table 1: Descriptive statistics

\begin{tabular}{clrrrrr} 
& Variable & Obs & \multicolumn{1}{c}{ Mean } & Std.Dev. & \multicolumn{1}{c}{ Min } & \multicolumn{1}{c}{ Max } \\
\hline \multirow{3}{*}{ Input } & Education Expenditure & 299 & 4.631 & 2.256 & 1.098 & 13.220 \\
& Health expenditure & 299 & 2.805 & 1.461 & 0.418 & 9.087 \\
\cline { 2 - 6 } Output & Primary enrolment & 299 & 100.043 & 22.215 & 39.539 & 149.271 \\
& Secondary Enrolment & 298 & 43.391 & 25.428 & 6.547 & 107.804 \\
& Infant Mortality & 299 & 59.694 & 24.588 & 11.800 & 110.000 \\
& Life Expectancy & 299 & 57.245 & 7.139 & 42.595 & 74.276 \\
\cline { 2 - 6 } & GDP per capita & 299 & 2181.409 & 2817.394 & 221.096 & 12850.490 \\
& Inflation & 299 & 7.581 & 7.491 & -3.503 & 37.393 \\
\multirow{5}{*}{ Environmental } & Labour & 299 & 52.519 & 13.959 & 25.659 & 78.749 \\
& Military Expenditure & 299 & 1.664 & 1.160 & 0.143 & 5.984 \\
& Capital & 299 & 20.516 & 9.229 & 2.557 & 46.732 \\
& Government Effectiveness & 299 & -0.502 & 0.620 & -1.840 & 1.130 \\
& Political stability & 299 & -0.444 & 0.981 & -2.670 & 1.080 \\
& Rule of Law & 299 & -0.523 & 0.679 & -1.830 & 1.060 \\
& Voice and accountability & 299 & -0.345 & 0.717 & -1.780 & 0.980 \\
& Control of Corruption & 299 & -0.432 & 0.662 & -1.510 & 1.250 \\
& Regulatory quality & 299 & -0.458 & 0.571 & -1.489 & 1.127 \\
\cline { 2 - 6 }
\end{tabular}

\subsection{Average Bootstrapped Efficiency Results (2006-2018)}

Bootstrapped output-oriented (VAR) DEA efficiency model was run. The specification considers four outputs and two inputs. The four outputs include primary enrolment, secondary enrolment, infant mortality and life expectancy. The sets of input comprised of health and education expenditure. All results were calculated using the variables returns to scale (VRS) assumption. Applying two-step test for CRS as proposed by Simar and Wilson (2007), test result rejects CRS in favour of VRS. Following Simar and Wilson (1998) test of independence, the paper adopted smooth bootstrapping. Table 2 provides the first-stage results from both conventional and bootstrap. The DEA models capture an overall technical efficiency estimates for SSA countries from 2006 to 2018. Results in Table 6 shows that the bias-corrected efficiency scores aregreater than the original DEA efficiency scores. The results show that the average bootstrapped inefficiency is 48 percent. Least inefficiency was 33 percent in 2014 and at maximum of 51 percent in 2010. The result shows that SSA countries experienced considerable higher inefficiencies in spending between the years 2006 and 2018. 
Table 2: Technical efficiency scores

\begin{tabular}{rrrrrl|r|rrrrr}
\hline \multicolumn{9}{c}{ Conventional VRS model } \\
\hline Year & Mean & Std.Dev. & Min & Max & Ineff* & Year & Mean & Std.Dev. & Min & Max & Ineff* \\
\hline 2006 & 1.32 & 0.60 & 1 & 3.51 & 24 percent & 2006 & 1.53 & 0.66 & 1.04 & 3.98 & 34 percent \\
2007 & 1.37 & 0.65 & 1 & 3.25 & 27 percent & 2007 & 1.70 & 0.80 & 1.02 & 3.85 & 41 percent \\
2008 & 1.428 & 0.87 & 1 & 4.68 & 30 percent & 2008 & 1.705 & 0.98 & 1.022 & 5.336 & 41 percent \\
2009 & 1.451 & 0.88 & 1 & 4.17 & 31 percent & 2009 & 1.737 & 0.98 & 1.074 & 4.924 & 42 percent \\
2010 & 1.466 & 0.84 & 1 & 4.3 & 32 percent & 2010 & 2.041 & 1.27 & 1.013 & 6.605 & 51 percent \\
2011 & 1.399 & 0.71 & 1 & 3.75 & 29 percent & 2011 & 1.876 & 0.98 & 1.079 & 5.111 & 47 percent \\
2012 & 1.409 & 0.91 & 1 & 4.69 & 29 percent & 2012 & 1.932 & 1.47 & 1.004 & 7.224 & 48 percent \\
2013 & 1.299 & 0.55 & 1 & 2.85 & 23 percent & 2013 & 1.529 & 0.65 & 1.011 & 3.068 & 35 percent \\
2014 & 1.298 & 0.63 & 1 & 3.42 & 23 percent & 2014 & 1.496 & 0.62 & 1.004 & 3.529 & 33 percent \\
2015 & 1.346 & 0.76 & 1 & 4.16 & 26 percent & 2015 & 1.762 & 1.08 & 1.018 & 5.753 & 43 percent \\
2016 & 1.399 & 0.77 & 1 & 3.66 & 29 percent & 2016 & 1.715 & 0.93 & 1.045 & 4.488 & 42 percent \\
2017 & 1.411 & 0.75 & 1 & 3.54 & 29 percent & 2017 & 1.822 & 1.00 & 1.043 & 4.813 & 45 percent \\
2018 & 1.407 & 0.71 & 1 & 3.29 & 29 percent & 2018 & 1.793 & 0.9 & 1.033 & 4.168 & 44 percent \\
Total & 1.739 & 0.96 & 1 & 5.82 & 43 percent & Total & 1.917 & 1.04 & 1.061 & 6.268 & 48 percent \\
\hline
\end{tabular}

\subsection{Relative efficiency scores for government spending in SSA countries}

The study analysed DEA output-oriented efficiency scores with CRS and VRS for 23 SSA countries for the period 2006 to 2018. Both CRS and VRS efficiency were estimated in order to assess whether inefficiency is due to scale efficiency or pure efficiency. Output-oriented DEA model maximizes output given a fixed level of inputs. The major goal of governments is to maximize social welfare of the public through public provision of goods and services while faced with constrained public resources. In this study 23 countries were taken as DMUs in order to evaluate their relative efficiency in terms of output variables (Primary enrolment, secondary enrolment, infant mortality and life expectancy).

Table 3 provides the output oriented efficiency scores when constant returns to scale is considered (CCR model). The average efficiency score is 0.68 implying that on average the SSA countries could have increased the output level by 32 percent by allocating the same spending. This denotes that SSA countries could improve government performance without necessarily increasing spending.

Guinea-Bissau is the most efficient country and the only country that is performing on the efficiency frontier while the other countries are performing below this frontier. Lesotho is the least efficient country with an average efficiency score of 0.264 denoting that it could increase output by 
73.6percent with the same level of resources. Lesotho inefficiency in government spending is explained by poor public financial management, political instability and high recurrent expenditure (Adeniran et al., 2018). Cameroon, Central African Republic, Guinea, Guinea-Bissau, Kenya, Mauritius, Nigeria and Sudan show efficient expenditure for some periods between 2006 and 2018 while Benin, Botswana, Burkina Faso, Burundi, Cape Verde, Ghana, Lesotho, Malawi, Rwanda, Senegal, and South African were consistently inefficient for the periods 2006-2018. 
Table 3: CCR Efficiency Scores (2006-2018) output oriented

\begin{tabular}{|c|c|c|c|c|c|c|c|c|c|c|c|c|c|c|c|}
\hline Country & 2006 & 2007 & 2008 & 2009 & 2010 & 2011 & 2012 & 2013 & 2014 & 2015 & 2016 & 2017 & 2018 & Average & Rank \\
\hline Benin & 0.61 & 0.56 & 0.54 & 0.49 & 0.57 & 0.58 & 0.55 & 0.74 & 0.64 & 0.45 & 0.65 & 0.70 & 0.70 & 0.60 & 14 \\
\hline Botswana & 0.97 & 0.81 & 0.69 & 0.44 & 0.64 & 0.49 & 0.45 & 0.47 & 0.64 & 0.69 & 0.63 & 0.48 & 0.53 & 0.61 & 13 \\
\hline Burkina Faso & 0.45 & 0.44 & 0.47 & 0.36 & 0.39 & 0.35 & 0.48 & 0.48 & 0.49 & 0.42 & 0.53 & 0.49 & 0.54 & 0.45 & 20 \\
\hline Burundi & 0.66 & 0.78 & 0.45 & 0.45 & 0.44 & 0.36 & 0.36 & 0.58 & 0.38 & 0.37 & 0.44 & 0.50 & 0.51 & 0.48 & 19 \\
\hline Cameroon & 0.72 & 0.86 & 0.76 & 0.71 & 0.80 & 0.79 & 0.95 & 1.00 & 1.00 & 0.97 & 1.00 & 1.00 & 1.00 & 0.89 & 5 \\
\hline Cape Verde & 0.40 & 0.46 & 0.48 & 0.49 & 0.56 & 0.56 & 0.58 & 0.66 & 0.73 & 0.73 & 0.69 & 0.75 & 0.89 & 0.61 & 12 \\
\hline $\begin{array}{l}\text { Central Africa } \\
\text { Republic }\end{array}$ & 0.91 & 1.00 & 1.00 & 1.00 & 1.00 & 1.00 & 1.00 & 1.00 & 1.00 & 1.00 & 1.00 & 1.00 & 1.00 & 0.99 & 3 \\
\hline Ghana & 0.50 & 0.59 & 0.41 & 0.30 & 0.41 & 0.37 & 0.39 & 0.48 & 0.50 & 0.42 & 0.40 & 0.51 & 0.54 & 0.45 & 21 \\
\hline Guinea & 0.81 & 0.88 & 0.98 & 1.00 & 1.00 & 1.00 & 1.00 & 1.00 & 0.82 & 0.61 & 0.81 & 0.67 & 0.68 & 0.87 & 6 \\
\hline Guinea-Bissau & 1.00 & 1.00 & 1.00 & 1.00 & 1.00 & 1.00 & 1.00 & 1.00 & 1.00 & 1.00 & 1.00 & 1.00 & 1.00 & 1.00 & 1 \\
\hline Kenya & 0.49 & 0.60 & 0.67 & 0.49 & 0.62 & 0.53 & 0.87 & 1.00 & 1.00 & 0.61 & 0.51 & 0.53 & 0.57 & 0.65 & 11 \\
\hline Lesotho & 0.31 & 0.32 & 0.25 & 0.27 & 0.26 & 0.22 & 0.21 & 0.29 & 0.27 & 0.25 & 0.24 & 0.25 & 0.29 & 0.26 & 23 \\
\hline Malawi & 0.60 & 0.66 & 0.68 & 0.60 & 0.69 & 0.50 & 0.67 & 0.69 & 0.58 & 0.51 & 0.47 & 0.47 & 0.50 & 0.58 & 16 \\
\hline Mauritania & 0.48 & 0.53 & 0.75 & 0.67 & 0.84 & 0.75 & 0.72 & 0.89 & 1.00 & 0.93 & 1.00 & 0.93 & 0.88 & 0.80 & 8 \\
\hline Mauritius & 1.00 & 0.95 & 0.97 & 1.00 & 1.00 & 1.00 & 1.00 & 1.00 & 1.00 & 1.00 & 1.00 & 1.00 & 1.00 & 0.99 & 2 \\
\hline Mozambique & 0.33 & 0.43 & 0.47 & 0.38 & 0.42 & 0.39 & 0.42 & 0.59 & 0.55 & 0.39 & 0.43 & 0.41 & 0.35 & 0.43 & 22 \\
\hline Niger & 0.57 & 0.70 & 0.51 & 0.49 & 0.52 & 0.46 & 0.50 & 0.58 & 0.74 & 0.46 & 0.59 & 0.56 & 0.40 & 0.54 & 17 \\
\hline Nigeria & 1.00 & 1.00 & 0.64 & 0.60 & 0.71 & 0.48 & 0.61 & 1.00 & 1.00 & 1.00 & 1.00 & 1.00 & 1.00 & 0.85 & 7 \\
\hline Rwanda & 0.58 & 0.45 & 0.54 & 0.54 & 0.54 & 0.45 & 0.59 & 0.85 & 0.74 & 0.53 & 0.68 & 0.66 & 0.58 & 0.59 & 15 \\
\hline Senegal & 0.47 & 0.48 & 0.49 & 0.34 & 0.42 & 0.48 & 0.46 & 0.61 & 0.66 & 0.54 & 0.58 & 0.53 & 0.47 & 0.50 & 18 \\
\hline Seychelles & 0.53 & 0.55 & 0.64 & 0.70 & 0.72 & 0.63 & 0.69 & 0.85 & 0.91 & 0.80 & 0.89 & 0.89 & 1.00 & 0.75 & 9 \\
\hline South Africa & 0.65 & 0.68 & 0.73 & 0.72 & 0.82 & 0.69 & 0.69 & 0.65 & 0.72 & 0.63 & 0.61 & 0.67 & 0.83 & 0.70 & 10 \\
\hline Sudan & 1.00 & 1.00 & 1.00 & 1.00 & 1.00 & 0.95 & 0.91 & 0.89 & 0.93 & 0.81 & 0.97 & 1.00 & 1.00 & 0.96 & 4 \\
\hline Average & & & & & & & & & & & & & & 0.68 & \\
\hline Minimum & & & & & & & & & & & & & & 0.26 & \\
\hline
\end{tabular}

Table 4 compares the results of output-oriented DEA model based on BCC model. The average efficiency score was established to be 98.5 percent for SSA. Central Africa Republic, Mauritania, Guinea-Bissau, Mauritius, Nigeria, Rwanda, Seychelles, South Africa and Sudan were the most efficient countries in resource allocation. The expenditure was optimally utilized to attain education and health outcomes. Eight countries have efficiency score higher than 98.5 percent 
but did not operate on the frontier: Benin, Botswana, Cameroon, Cape Verde, Guinea and Lesotho. Six countries have efficiency score under the total average: Burkina Faso, Burundi, Ghana, Kenya, Mozambique, Niger and Senegal. Table 4 illustrates that nine countries located on the efficiency frontier and therefore labelled as the most efficient. These countries include: Central Africa Republic, Guinea-Bissau, Mauritania, Mauritius, Nigeria, Rwanda, Seychelles, South Africa and Sudan.

Table 4: BCC Efficiency Scores (2006-2018) output oriented

\begin{tabular}{|c|c|c|c|c|c|c|c|c|c|c|c|c|c|c|c|}
\hline Country & 2006 & 2007 & 2008 & 2009 & 2010 & 2011 & 2012 & 2013 & 2014 & 2015 & 2016 & 2017 & 2018 & Average & Rank \\
\hline Benin & 1.00 & 1.00 & 1.00 & 1.00 & 1.00 & 1.00 & 1.00 & 1.00 & 1.00 & 1.00 & 1.00 & 1.00 & 1.00 & 1.00 & 10 \\
\hline Botswana & 1.00 & 1.00 & 1.00 & 1.00 & 1.00 & 0.99 & 0.98 & 0.99 & 0.98 & 1.00 & 0.99 & 0.98 & 0.98 & 0.99 & 15 \\
\hline Burkina Faso & 0.96 & 0.96 & 0.97 & 0.97 & 0.96 & 0.96 & 0.96 & 0.95 & 0.95 & 0.95 & 0.95 & 0.95 & 0.94 & 0.96 & 20 \\
\hline Burundi & 0.96 & 0.97 & 0.96 & 0.96 & 0.96 & 0.97 & 0.97 & 0.99 & 1.00 & 1.00 & 1.00 & 0.97 & 0.96 & 0.97 & 17 \\
\hline Cameroon & 0.98 & 0.97 & 0.97 & 0.97 & 0.96 & 0.98 & 0.99 & 1.00 & 1.00 & 1.00 & 1.00 & 1.00 & 1.00 & 0.99 & 16 \\
\hline Cape Verde & 1.00 & 0.99 & 1.00 & 1.00 & 1.00 & 1.00 & 1.00 & 1.00 & 1.00 & 1.00 & 1.00 & 1.00 & 1.00 & 1.00 & 11 \\
\hline Central Africa Republic & 1.00 & 1.00 & 1.00 & 1.00 & 1.00 & 1.00 & 1.00 & 1.00 & 1.00 & 1.00 & 1.00 & 1.00 & 1.00 & 1.00 & 1 \\
\hline Ghana & 0.96 & 0.95 & 0.94 & 0.94 & 0.94 & 0.95 & 0.95 & 0.95 & 0.95 & 0.95 & 0.94 & 0.94 & 0.94 & 0.95 & 22 \\
\hline Guinea & 0.98 & 0.98 & 0.99 & 1.00 & 1.00 & 1.00 & 1.00 & 1.00 & 1.00 & 1.00 & 1.00 & 1.00 & 1.00 & 1.00 & 12 \\
\hline Guinea-Bissau & 1.00 & 1.00 & 1.00 & 1.00 & 1.00 & 1.00 & 1.00 & 1.00 & 1.00 & 1.00 & 1.00 & 1.00 & 1.00 & 1.00 & 1 \\
\hline Kenya & 0.87 & 0.93 & 0.92 & 0.89 & 0.89 & 0.92 & 0.95 & 1.00 & 1.00 & 0.93 & 0.93 & 0.94 & 0.94 & 0.93 & 23 \\
\hline Lesotho & 0.95 & 1.00 & 1.00 & 1.00 & 1.00 & 1.00 & 1.00 & 1.00 & 1.00 & 1.00 & 1.00 & 1.00 & 1.00 & 1.00 & 13 \\
\hline Malawi & 1.00 & 1.00 & 1.00 & 1.00 & 1.00 & 0.94 & 1.00 & 1.00 & 1.00 & 1.00 & 1.00 & 1.00 & 1.00 & 1.00 & 14 \\
\hline Mauritania & 1.00 & 1.00 & 1.00 & 1.00 & 1.00 & 1.00 & 1.00 & 1.00 & 1.00 & 1.00 & 1.00 & 1.00 & 1.00 & 1.00 & 1 \\
\hline Mauritius & 1.00 & 1.00 & 1.00 & 1.00 & 1.00 & 1.00 & 1.00 & 1.00 & 1.00 & 1.00 & 1.00 & 1.00 & 1.00 & 1.00 & 1 \\
\hline Mozambique & 1.00 & 0.99 & 0.98 & 0.97 & 0.97 & 0.96 & 0.96 & 0.96 & 0.96 & 0.93 & 0.92 & 0.92 & 0.93 & 0.96 & 19 \\
\hline Niger & 0.97 & 0.97 & 0.97 & 0.96 & 0.96 & 0.95 & 0.95 & 0.94 & 0.94 & 0.94 & 0.94 & 0.94 & 0.94 & 0.95 & 21 \\
\hline Nigeria & 1.00 & 1.00 & 1.00 & 1.00 & 1.00 & 1.00 & 1.00 & 1.00 & 1.00 & 1.00 & 1.00 & 1.00 & 1.00 & 1.00 & 1 \\
\hline Rwanda & 1.00 & 1.00 & 1.00 & 1.00 & 1.00 & 1.00 & 1.00 & 1.00 & 1.00 & 1.00 & 1.00 & 1.00 & 1.00 & 1.00 & 1 \\
\hline Senegal & 0.97 & 0.95 & 0.96 & 0.95 & 0.96 & 0.96 & 0.96 & 0.96 & 0.97 & 0.97 & 0.97 & 0.97 & 0.97 & 0.96 & 18 \\
\hline Seychelles & 1.00 & 1.00 & 1.00 & 1.00 & 1.00 & 1.00 & 1.00 & 1.00 & 1.00 & 1.00 & 1.00 & 1.00 & 1.00 & 1.00 & 1 \\
\hline South Africa & 1.00 & 1.00 & 1.00 & 1.00 & 1.00 & 1.00 & 1.00 & 1.00 & 1.00 & 1.00 & 1.00 & 1.00 & 1.00 & 1.00 & 1 \\
\hline Sudan & 1.00 & 1.00 & 1.00 & 1.00 & 1.00 & 1.00 & 1.00 & 1.00 & 1.00 & 1.00 & 1.00 & 1.00 & 1.00 & 1.00 & 1 \\
\hline Average & & & & & & & & & & & & & & 0.98 & \\
\hline Minimum & & & & & & & & & & & & & & 0.93 & \\
\hline
\end{tabular}


Table 5 presented scale efficiency (SE) of government spending for SSA countries. SE measure is obtained by comparing CRS-efficiency scores with VRS-efficiency. CRS-efficiency score represents overall technical efficiency (OTE). OTE is the inefficiency due to the configuration of inputs and output. The VRS efficiency score represents pure technical efficiency (PTE). PTE measures inefficiencies due to government interventions or managerial skills in decision making process. Scale efficiency is therefore obtained as:

$$
S E=O T E / P T E
$$

Scale efficiency scores help decision makers to understand the reason of inefficiency in CCR model. On average, scale efficiency for the sampled SSA countries is 0.69 compared to pure scale efficiency of 0.98 . Based on this finding, the source of the technical inefficiency of the SSA countries' government spending is the scale inefficiency instead of pure technical efficiency. The result implies SSA countries mostly suffer from the problem of operating at the wrong scale of operations. This finding could be attributed to constraints in domestic resource mobilization and low governance quality captured by public investment inefficiency. Further, inadequate managerial and organizational could contribute to the inefficiencies. 
Table 5: Scale Efficiency Scores (2006-2018) output oriented

\begin{tabular}{|c|c|c|c|c|c|c|c|c|c|c|c|c|c|c|c|}
\hline Country & 2006 & 2007 & 2008 & 2009 & 2010 & 2011 & 2012 & 2013 & 2014 & 2015 & 2016 & 2017 & 2018 & Average & Rank \\
\hline Benin & 0.61 & 0.56 & 0.54 & 0.49 & 0.57 & 0.58 & 0.55 & 0.74 & 0.64 & 0.45 & 0.65 & 0.70 & 0.70 & 0.60 & 13 \\
\hline Botswana & 0.97 & 0.81 & 0.69 & 0.44 & 0.64 & 0.49 & 0.46 & 0.48 & 0.65 & 0.69 & 0.64 & 0.49 & 0.54 & 0.61 & 12 \\
\hline Burkina Faso & 0.47 & 0.46 & 0.48 & 0.37 & 0.41 & 0.36 & 0.50 & 0.50 & 0.52 & 0.44 & 0.56 & 0.52 & 0.58 & 0.47 & 21 \\
\hline Burundi & 0.69 & 0.81 & 0.47 & 0.47 & 0.46 & 0.37 & 0.37 & 0.58 & 0.38 & 0.37 & 0.44 & 0.51 & 0.52 & 0.50 & 20 \\
\hline Cameron & 0.74 & 0.88 & 0.79 & 0.73 & 0.83 & 0.80 & 0.96 & 1.00 & 1.00 & 0.97 & 1.00 & 1.00 & 1.00 & 0.90 & 5 \\
\hline Cape Verde & 0.94 & 0.92 & 0.59 & 0.64 & 0.55 & 0.46 & 0.39 & 0.58 & 0.38 & 0.38 & 0.44 & 0.51 & 0.52 & 0.56 & 18 \\
\hline $\begin{array}{l}\text { Central Africa } \\
\text { Republic }\end{array}$ & 0.91 & 1.00 & 1.00 & 1.00 & 1.00 & 1.00 & 1.00 & 1.00 & 1.00 & 1.00 & 1.00 & 1.00 & 1.00 & 0.99 & 3 \\
\hline Ghana & 1.02 & 0.92 & 0.59 & 0.64 & 0.55 & 0.46 & 0.39 & 0.58 & 0.38 & 0.38 & 0.44 & 0.51 & 0.52 & 0.57 & 17 \\
\hline Guinea & 0.82 & 0.90 & 0.99 & 1.00 & 1.00 & 1.00 & 1.00 & 1.00 & 0.82 & 0.61 & 0.81 & 0.67 & 0.68 & 0.87 & 6 \\
\hline Guinea-Bissau & 1.00 & 1.00 & 1.00 & 1.00 & 1.00 & 1.00 & 1.00 & 1.00 & 1.00 & 1.00 & 1.00 & 1.00 & 1.00 & 1.00 & 1 \\
\hline Kenya & 0.56 & 0.65 & 0.73 & 0.54 & 0.69 & 0.58 & 0.92 & 1.00 & 1.00 & 0.66 & 0.54 & 0.57 & 0.61 & 0.70 & 11 \\
\hline Lesotho & 0.33 & 0.32 & 0.25 & 0.27 & 0.26 & 0.22 & 0.21 & 0.29 & 0.27 & 0.25 & 0.24 & 0.25 & 0.29 & 0.27 & 23 \\
\hline Malawi & 0.60 & 0.66 & 0.68 & 0.60 & 0.69 & 0.52 & 0.67 & 0.69 & 0.58 & 0.51 & 0.47 & 0.47 & 0.50 & 0.59 & 15 \\
\hline Mauritania & 0.48 & 0.53 & 0.75 & 0.67 & 0.84 & 0.75 & 0.72 & 0.89 & 1.00 & 0.93 & 1.00 & 0.93 & 0.88 & 0.80 & 8 \\
\hline Mauritius & 1.00 & 0.95 & 0.97 & 1.00 & 1.00 & 1.00 & 1.00 & 1.00 & 1.00 & 1.00 & 1.00 & 1.00 & 1.00 & 0.99 & 2 \\
\hline Mozambique & 0.33 & 0.44 & 0.48 & 0.39 & 0.43 & 0.41 & 0.43 & 0.61 & 0.57 & 0.42 & 0.47 & 0.44 & 0.38 & 0.45 & 22 \\
\hline Niger & 0.59 & 0.72 & 0.53 & 0.51 & 0.54 & 0.48 & 0.53 & 0.61 & 0.79 & 0.49 & 0.63 & 0.59 & 0.42 & 0.57 & 16 \\
\hline Nigeria & 1.00 & 1.00 & 0.64 & 0.60 & 0.71 & 0.48 & 0.61 & 1.00 & 1.00 & 1.00 & 1.00 & 1.00 & 1.00 & 0.85 & 7 \\
\hline Rwanda & 0.58 & 0.45 & 0.54 & 0.54 & 0.54 & 0.45 & 0.59 & 0.85 & 0.74 & 0.53 & 0.68 & 0.66 & 0.58 & 0.59 & 14 \\
\hline Senegal & 0.48 & 0.51 & 0.51 & 0.36 & 0.44 & 0.50 & 0.48 & 0.63 & 0.68 & 0.56 & 0.59 & 0.54 & 0.48 & 0.52 & 19 \\
\hline Seychelles & 0.53 & 0.55 & 0.64 & 0.70 & 0.72 & 0.63 & 0.69 & 0.85 & 0.91 & 0.80 & 0.89 & 0.89 & 1.00 & 0.75 & 9 \\
\hline South Africa & 0.65 & 0.68 & 0.73 & 0.72 & 0.82 & 0.69 & 0.69 & 0.65 & 0.72 & 0.63 & 0.61 & 0.67 & 0.83 & 0.70 & 10 \\
\hline Sudan & 1.00 & 1.00 & 1.00 & 1.00 & 1.00 & 0.95 & 0.91 & 0.89 & 0.93 & 0.81 & 0.97 & 1.00 & 1.00 & 0.96 & 4 \\
\hline Average & & & & & & & & & & & & & & 0.69 & \\
\hline Minimum & & & & & & & & & & & & & & 0.45 & \\
\hline
\end{tabular}




\subsection{Determinant of efficiency}

Bias-corrected coefficients of the truncated regression estimates were obtained through the two-step approach. First stage efficiency scores are not free from serial correlation hence second stage estimates are inconsistent and biased (Simar and Wilson, 1999). A bootstrap procedure overcomes this problem. Table 6 presents the bias-corrected coefficients of the truncated regression model that provides the estimates for the sources of inefficiencies in government spending for SSA countries. Capital formation significantly relates to SSA spending efficiency though the effect is negative. The findings have established that domestic saving positively and significantly improve the efficiency of government spends for SSA countries. The result shows that inflation positively impacts efficiency of government spending albeit insignificantly. The result contrast Hauner and Kyobe (2010) findings who found that inflation negatively affects efficiency as it complicates the planning process of government expenditure.

Table 6: Truncated bootstrapped two-stage regression (dependent variable: BCC index)

VARIABLES

Capital formation

Inflation

Military

Ln(GDP per capita)

Labour force

Domestic Saving

Primary enrolment

Secondary enrolment

Government effectiveness

Political stability

Rule of Law

Voice and Accountability

Corruption of corruption

Regulatory quality
Estimates

$-0.0851 * * *$

(0.0173)

0.00839

(0.0132)

$-0.0609$

(0.117)

$-1.013 * * *$

(0.319)

$-0.0159$

$(0.0110)$

$0.0482 * * *$

(0.0120)

$-0.00577$

$(0.00629)$

$0.0749 * * *$

(0.0123)

0.174

(0.634)

$2.021 * * *$

(0.257)

$-4.220 * * *$

(0.684)

$-0.845 * *$

$(0.342)$

0.603

$(0.480)$

$-0.965^{*}$ 
Observations

\begin{tabular}{|c|c|}
\hline Simar\& Wilson & 7) eff. Analy \\
\hline Number of obs & $=299$ \\
\hline Number of boot & eps $=$ \\
\hline Wald chi2(14) & $=128.71$ \\
\hline Prob>chi2(14) & $=0.0000$ \\
\hline
\end{tabular}

Natural log of income per capita negatively and significantly relate to SSA spending efficiency. An improvement of GDP per capita by 1percent will lead to a decrease in spending efficiency by 10.13 percent. This result contradicts popular view in literature that predicts a positive impact of GDP per capita on spending efficiency. For example, previous research has shown that higher output growth improves spending efficiency (Levine and Renelt, 1992; Saleh and Harvie, 2005). Domestic saving significantly improves the efficiency of government spending of SSA countries. Both primary and secondary enrolment rate were used as education indicator. Secondary school enrolment significantly improves the efficiency of government spending. The result reinforces studies by Mankiwet al. (1992) and Barro (1991) who asserted that higher education achievement improves spending efficiency.

The estimates for institutional quality indices have mixed results. Government effectiveness, political stability and control of corruption have positive effect on efficiency of government spending. An improvement in political stability significantly translates to better spending efficiency. Both control of corruption and government effectiveness improve efficiency though insignificantly. Rule of law, voice and accountability and regulatory quality negatively influence efficiency of spending. Higher income is associated with an improvement in education and health outcome (Afonso et al., 2005: Afonso and Aubyn, 2006; Herrera and Pang, 2005). Empirical findings have shown that institutions are key drivers of growth, financial development and spending efficiency. The degree of development of civil society impacts the efficiency spending (Putnam et al., 1994). Maintenance of rule of law has a significant and positive effect on efficiency of government expenditure. However, voice and accountability has significant negative influence on efficiency of government spending. This goes against priori expectation of positive association with efficiency. Evidence has established that controlling for corruption increases efficiency (Hauner and Kyobe, 2010). The regression result has established positive association between control for corruption and spending efficiency. 


\section{Discussion and Conclusion}

The study analysed the status of efficiency of government spending for 23 SSA countries for the periods 2006-2018 and environmental factors that explain inefficiency in government spending. Two-step bootstrap DEA was used to analyse the efficiency of government spending for SSA countries. Output-oriented DEA was also used to analyse the efficiency of government spending. The findings showed that the averagebias-corrected inefficiency score was 48 percent between 2006 and 2018 while the uncorrected inefficiency was 32.3 percent. SSA country experienced minimum spending inefficiency of 33 percent in 2014 and a maximum of 51 percent in 2010. The study established that, on average, SSA countries are relatively inefficient. SSA countries could have achieved the same level of output with 48 percent fewer resources, i.e. that government efficiency could improve without necessarily increasing spending. Individual country's efficiency scores and ranking positions of SSA countries reveal a wide dispersion in performance. Guinea-Bissau was the only efficient country. The average scale efficiency for SSA countries was different from the pure efficiency. Scale efficiency was established to be 68.7 percent and this demonstrated that SSA countries are not operating at optimal level.

Bias-corrected coefficients of the truncated regression estimates indicated that GDP per capital significantly cause distortion on the efficiency of government spending for SSA countries. Secondary school enrolment improves the efficiency of government spending across SSA countries. A rise in domestic saving improves efficiency of government spending while capital formation significantly distorts efficiency of spending. Political stability potentially improves efficiency of spending. Control of corruption improves efficiency of a country spending though the effect is non-significant. Surprisingly, the finding demonstrates accountability and regulatory quality significant distort spending efficiency of SSA government spending. Based on the findings, SSA countries can improve on health and education expenditure efficiency. To achieve this, governments need to adopt policies that improve the efficiency of government health and education spending. Efficient outcome of health and education spending can be realized by government strengthening monitoring unit of government expenditure with decentralization strategies closely linked to each sector strategies. SSA countries also need to improve transparency in management of public resources.

SSA countries should provide conducive environment for private sector development. This can be achieved through tax exceptions to new businesses, improving ease of doing business and creating business hubs that attract investors. These policies will consequently improve GPD per capita, domestic savings and capital formation. SSA countries should prioritize 
institutional quality such as political stability, rule of law and regulatory quality. Well-structured political transition that takes into account inclusivity should be adopted. Strong and independent institutions should be established to deal with property rights. The monetary institutions should be accorded independence and strengthened in order control inflation and money supply. SSA countries need also to strengthen and develop public finance management which focuses on fiscal planning reforms, implementation and monitoring and legal framework.

\section{Acknowledgment}

The author would like to acknowledge the financial support from the African Economic Research Consortium (AERC) which was awarded towards Phd scholarship in economics.

\section{References:}

1. Adeniran, A. P., Ekeruche, M. A., Bodunrin, O. S., \& Ali, A. A. (2018). Africa's Rising Debt: Implications for Development Financing and a Sustainable Debt Management Approach.

2. Afonso, A., \&Aubyn, M. S. (2006). Cross-country efficiency of secondary education provision: A semi-parametric analysis with nondiscretionary inputs. Economic modelling, 23(3), 476-491.

3. Afonso, A., \&Fernandes, S. (2003). Efficiency of local government spending: Evidence for the Lisbon Region. Available at SSRN 470481.

4. Afonso, A., \&Kazemi, M. (2017). Assessing public spending efficiency in 20 OECD countries. In Inequality and Finance in Macrodynamics (pp. 7-42). Springer, Cham.

5. Afonso, A., Ebert, W., Schuknecht, L., \&Thöne, M. (2005). Quality of public finances and growth.

6. Barro, R. J. (1991). Economic growth in a cross section of countries. The quarterly journal of economics, 106(2), 407-443.

7. Cebula, R. J. (2003). Budget deficits and interest rates in Germany. International Advances in Economics Research, 9 (1), 64-68.

8. Chan, S. G., Ramly, Z., \& Karim, M. Z. A. (2017). Government spending efficiency on economic growth: Roles of value-added tax. Global Economic Review, 46(2), 162-188.

9. Charnes, A., Cooper, W. W., \& Rhodes, E. (1978). Measuring the efficiency of decision making units. European journal of operational research, 2(6), 429-444.

10. Gupta, S., \&Verhoeven, M. (2001). The efficiency of government expenditure: experiences from Africa. Journal of policy modeling, 23(4), 433-467. 
11. Hauner, D., \&Kyobe, A. (2010). Determinants of government efficiency. World Development, 38(11), 1527-1542.

12. Hernández-Catá, E., Schwab, K., \&Lopez-Claros, A. (2004). The Africa competitiveness report 2004. World Economic Forum.

13. Herrera, S., \& Pang, G. (2005). Efficiency of public spending in developing countries: An efficiency frontier approach Vol. 1, 2 \& 3. The World Bank

14. Hsu, Y. C. (2013). The efficiency of government spending on health: Evidence from Europe and Central Asia. The Social Science Journal, 50(4), 665-673.

15. Kimaro, E. L., Keong, C. C., \& Sea, L. L. (2017). Government expenditure, efficiency and economic growth: a panel analysis of Sub Saharan African low income countries. African Journal of Economic Review, 5(2), 34-54.

16. Levine, R., \&Renelt, D. (1992). A sensitivity analysis of cross-country growth regressions. The American economic review, 942-963.

17. Mandl, U., Dierx, A., \&Ilzkovitz, F. (2008). The effectiveness and efficiency of public spending (No. 301). Directorate General Economic and Financial Affairs (DG ECFIN), European Commission.

18. Mankiw, N. G., Romer, D., \& Weil, D. N. (1992). A contribution to the empirics of economic growth. The quarterly journal of economics, 107(2), 407-437.

19. Prasetyo, A. D., \&Zuhdi, U. (2013). The Government Expenditure Efficiency towards the human development. Procedia Economics and Finance, 5, 615-622.

20. Putnam, R. D., Leonardi, R., \&Nanetti, R. Y. (1994). Making democracy work: Civic traditions in modern Italy. Princeton university press.

21. Rahmayanti, Y., \& Horn, T. (2010). Expenditure efficiency and the optimal size of government in developing countries (No. 10-20).

22. Rajkumar, A. S., \&Swaroop, V. (2008). Public spending and outcomes: Does governance matter? Journal of development economics, 86(1), 96-111.

23. Rayp, G., \& Van De Sijpe, N. (2007). Measuring and explaining government efficiency in developing countries. The Journal of Development Studies, 43(2), 360-381.

24. Saleh, A. S., \&Harvie, C. (2005). The budget deficit and economic performance: A survey. The Singapore Economic Review, 50(02), 211-243

25. Simar, L., \& Wilson, P. W. (1999). Estimating and bootstrapping Malmquist indices. European journal of operational research, 115(3), 459-471. 
26. Simar, L., \& Wilson, P. W. (2007). Estimation and inference in twostage, semi-parametric models of production processes. Journal of econometrics, 136(1), 31-64.

27. Sung, N. (2007). Information technology, efficiency and productivity: evidence from Korean local governments. Applied Economics, 39(13), 1691-1703.

28. Tanzi, V. (2004). Measuring efficiency in public expenditure. In paper presentato in Conference on Public Expenditure Evaluation and Growth dellaBancaMondiale.

29. Teorell, J., Charron, N., Samanni, M., Holmberg, S., \& Rothstein, B. (2011). The quality of government dataset. The Quality of Government Institute University of Göteborg. Göteborg.

30. Wang, E. C., \&Alvi, E. (2011). Relative efficiency of government spending and its determinants: Evidence from East Asian countries. Eurasian Economic Review, 1(1), 3-28. 